\title{
Forging Partnerships with Other Federal Programs: NASA and the National Science Foundation (NSF) through Scientific Ocean Drilling
}

Clive R. Neal - University of Notre Dame, IN (cneal@nd.edu)

Sean P.S. Gulick - University of Texas at Austin, TX (sean@ig.utexas.edu)

Brett Baker - University of Texas at Austin, TX (acidophile@gmail.com)

Steve D'Hondt - University of Rhode Island, RI (dhondt@uri.edu)

Nobu Eguchi - Japan Agency for Marine-Earth Science and Technology (neguchi@jamstec.go.jp)

Tracy Gregg - University at Buffalo, NY (tgregg@buffalo.edu)

Fumio Inagaki - Japan Agency for Marine-Earth Science and Technology (inagaki@jamstec.go.jp)

Anthony Koppers - Oregon State University, OR (anthony.koppers@oregonstate.edu)

Charity M. Lander - Southwest Research Institute, CO (charity.lander@swri.org)

Daniel Moriarty - NASA Goddard Space Flight Center, MD (daniel.p.moriarty@nasa.gov)

Yuki Morono - Japan Agency for Marine-Earth Science and Technology (morono@jamstec.go.jp)

Beth Orcutt - Bigelow Laboratory for Ocean Sciences, ME (borcutt@bigelow.org)

Ross Potter - Brown University, RI (ross_potter@brown.edu)

Maureen Raymo - LDEO, Columbia University, NY (raymo@1deo.columbia.edu)

Mitch Schulte - NASA (mitchell.d.schulte@nasa.gov)

Sonia Tikoo - Stanford University, CA (smtikoo@stanford.edu)

Marta Torres - Oregon State University, OR (marta.torres@oregonstate.edu)
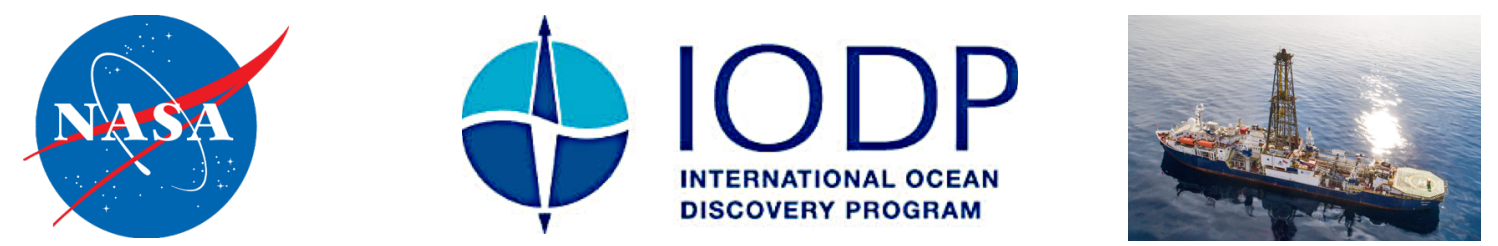

RECOMMENDATION: We urge a concerted effort between NASA and NSF be created to establish closer research cooperation and collaboration that takes advantage of scientific ocean drilling (IODP) infrastructure, data, and samples to advance analogue research. For example, the recent Research Coordination Networks within the NASA Astrobiology program could have this linkage as a goal, to strengthen ties within the community. NASA Earth science data could be used to expand the relevance of data obtained by scientific ocean drilling, including past sea level data. We are confident that this partnership would enable major scientific breakthroughs and facilitate new directions for ocean drilling research and robotic investigations of other planetary bodies. Justification for this is given below.

Introduction: The Planetary Science and Astrobiology Decadal survey Statement of Task, point \#8 states: "The opportunities for collaborative research that are relevant to science priorities between $S M D$ 's four science divisions (for example, comparative planetology approaches to exoplanet or astrobiology research); between NASA SMD and the other NASA mission directorates; between NASA and the NSF; between NASA and other US government entities; between NASA and private sector organizations; between NASA and its international partners". This white paper highlights potential collaborative research opportunities between the NASA-SMD and the National Science Foundation (NSF) that can be achieved through mutual scientific interests, and that can have a significant impact on Earth and planetary science over the next decade. These interests are focused on scientific ocean drilling and associated activities (i.e., borehole observatories, post expedition research using core and data), funded through the NSF and international partners.

Scientific Ocean Drilling. In 2018, scientific ocean drilling celebrated 50 years of thematic science that was encapsulated in a dedicated volume of Oceanography (Special Issue, 2019). Drilling in the 
oceans for scientific purposes began in the summer of 1968 with Leg 1 of the Deep Sea Drilling Project (DSDP, 1968-1983). This program transformed from a focus on exploration during DSDP to more targeted, hypothesis-driven science aimed at understanding fundamental processes during the Ocean Drilling Program (ODP, 1985-2003), the Integrated Ocean Drilling Program (IODP, 2003-2013), and the current International Ocean Discovery Program (IODP, 2013-2023) (Koppers et al., 2019). What started as a US-funded operation in 1968 with one drilling platform has grown into a leading international program with three platforms - R/V JOIDES Resolution (USA), D/V Chikyu (Japan), and mission specific platforms (shallow water drilling, ice-breakers, etc., coordinated by the European Consortium for Ocean Research Drilling).

The fifty years of observations and hypothesis testing through ocean drilling has enabled increasingly more sophisticated understanding of how planet Earth works and evolves. As with planetary science at NASA, scientific ocean drilling has been guided by community-driven science plans since the conclusion of DSDP (Koppers and Austin (2019). The ODP was guided by several documents that supported multiple and evolving themes (Report of the Second Conference on Scientific Ocean Drilling, Anonymous, 1987; Understanding Our Dynamic Earth through Ocean Drilling, Ocean Drilling Program-ODP, 1996). The Integrated Ocean Drilling Program (IODP), was guided by a new science plan, Earth, Oceans and Life: Scientific Investigation of the Earth System using Multiple Drilling Platforms and New Technologies, from 2003-2013 (Coffin and McKenzie, 2001) that contained three themes: The Deep Biosphere and Subseafloor Ocean; Environmental Change, Processes, and Effects; and Solid Earth Cycles and Geodynamics. This was followed by the International Ocean Discovery Program and the number of themes grew to include new research avenues toward better understanding of processes and natural hazards on human timescales. The current science plan, Illuminating Earth's Past, Present and Future, contains four themes: Climate and Ocean Change, Biosphere Frontiers, Earth Connections, and Earth in Motion (2013-2023).

A new approach is now being developed that extends long-range planning beyond the traditional 10-year time line. Exploring Earth by Scientific Ocean Drilling: 2050 Science Framework describes seven Strategic Objectives (Habitability and Life, Plate Tectonics, Earth System Feedback, Climate, Tipping Points, Global Cycles, and Natural Hazards), five Flagship Initiatives (Ground-truthing Future Climate Change, Probing the Deep Earth, Earthquake and Tsunami Hazards, Ocean Health, and Life and its Origin) and four Enabling Elements (Broader Impacts \& Outreach, Land to Sea, Terrestrial to Extraterrestrial, and Technology Development and "Big Data" Analytics). This new framework encourages inclusion of projects that would take $>10$ years to accomplish. This document builds on the successes of past programs and looks forward to the future. There will be regular reviews (every $\sim 5$ years) reviews and updates to the framework so new discoveries and ideas can be incorporated.

Relevance to NSF and Scientific Ocean Drilling. The new 2050 Science Framework advocates closer collaborations with other federal and international agencies. Of particular relevance for this white paper are 2050 Science Framework emphases on understanding the inner workings of our planet (which can be an analogue to study other terrestrial planets, moons, or exoplanets), habitability of Earth and other planetary bodies, exploring the limits of life, and understanding the effects of extraterrestrial impacts (physical and environmental processes). These emphases have direct synergies with NASA planetary science research (see below). Collaborative efforts between NASA and scientific ocean drilling to study the features of other terrestrial planets and moons, in an analogue reference frame in Earth's ocean basins, will advance understanding of planetary evolution, as well as assess the potential for indigenous life elsewhere in the Solar System (e.g., Mars, ocean worlds) or neighboring planetary systems. Furthermore, the many advances in understanding paleoclimate research conducted through scientific ocean drilling have never been formally linked to/coordinated with the modern climate data that NASA has been collecting for the last 50+ years. NASA also has technology development 
programs that naturally cross-fertilize with scientific ocean drilling (e.g., drilling technologies, longterm monitoring instruments, life detection instruments).

Relevance to NASA-SMD. NASA-SMD recently published Explore Science 2020-2024: A Vision for Science Excellence. This document represents a departure from past science plans in that it presents four cross-cutting priorities and accompanying strategies that reflect NASA's shared values. Within Priority 3: Interconnectivity and Partnerships, the document states "SMD recognizes the important role that NASA Centers, other federal agencies, private industry, academia, non-profits, community-based organizations, and international partners play in helping make our scientific vision a reality." Two strategies are highlighted-3.2 Actively seek collaborations with international partners based on their unique capabilities and mutual scientific goals, and 3.3 Actively engage with other federal agencies to make more informed decisions, cooperate in scientific research, and pursue partnerships that further national interests. By establishing closer collaborative efforts with NSF and scientific ocean drilling, NASA-SMD will accomplish Strategy 3.3. Because scientific ocean drilling is an international program, this closer collaboration will also go a long way to accomplishing Strategy 3.2. By opening new research avenues through this new collaboration, NASA-SMD could also fulfill Strategy 3.4 (Provide increasing opportunities for research institutions, including academia and non-profits, to contribute to SMD's mission).

NASA-SMD Planetary Science Division (PSD) seeks to address four overarching major questions that they seek to address through missions and research (https://science.nasa.gov/solarsystem/big-questions). These are:

1a. How did life begin and evolve on Earth, and has it evolved elsewhere in the Solar System?

1b. How did the Solar System evolve to its current state?

1c. How did the Sun's family of planets and minor bodies originate?

1d. What are the characteristics of the Solar System that lead to the origins of life?

NASA-SMD Earth Science Division (ESD) seeks to address four different overarching major questions that they seek to address through missions and research (https://science.nasa.gov/earthscience/big-questions). These are:

2a. How is the global Earth system changing?

2b. What causes these changes in the Earth system?

2c. How will the Earth system change in the future?

2d. How can Earth system science provide societal benefit?

The synergies between these Planetary and Earth Science questions with scientific ocean drilling are highlighted below in more detail.

Integrating NASA \& NSF Research using Scientific Ocean Drilling. In this white paper, we highlight four planetary research areas within which NASA research could inform scientific ocean drilling, and, in turn, scientific ocean drilling and NSF initiatives could inform NASA research. These areas include detection and limits of life in the subsurface, understanding the inner workings of terrestrial planets, testing models of the extraterrestrial impact process, and climate dynamics and tipping points.

Life. Two of the four major science questions posed by NASASMD-PSD (\#1 a and \#1d above) are related to life beyond Earth Understanding habitability and the limits of life are directly advanced by studies on Earth, especially through scientific ocean drilling. The debate over the existence of life off Earth

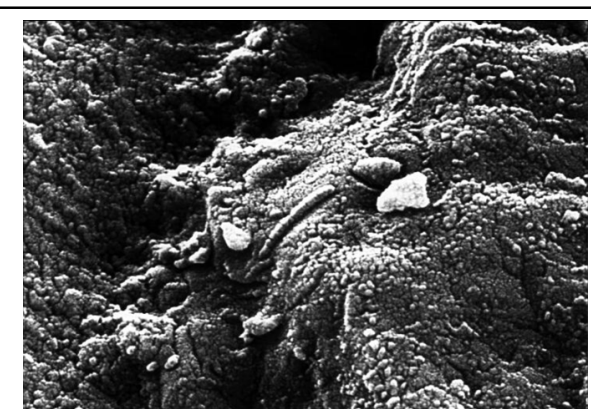

Figure 1: high-resolution SEM image of the "Mars worm", $1 / 100^{\text {th }}$ the width of a human hair, in ALH84001. Image credit: NASA. 
centers around microbial activity, a topic that exploded in interest after the discovery of putative fossil evidence of microbial life in martian meteorite ALH84001 (Fig. 1; McKay et al., 1996). In addition, there is overwhelming evidence for water flowing on the surface of Mars during some points in the history of the red planet. Although the fossil evidence has been disproven, Mars is considered to at least have been at one time "habitable", and maybe extant life still exists at depth (Stamenkovic et al., 2019).

Deep ocean exploration transformed our understanding of habitability with the discovery of deep sea hydrothermal vents in the 1970s. Our understanding of deep seafloor hydrothermal communities has driven our understanding of Ocean Worlds, where hydrothermal alteration may support life (Lang and Brazelton, 2020). Indeed, the marine subsurface has been identified as a prime target for understanding life under extreme energy limitation, relevant to several astrobiological targets of interest like Europa, Enceladus, and Mars (Jones et al., 2018; Dzaugis et al., 2018; Stamenkovic et al., 2019). Likewise, several recent IODP expeditions have specifically focused on determining signatures of life in the marine subsurface with an eye toward understanding habitability and biosignatures (D’Hondt et al., 2019; Früh-Green and Orcutt, 2019).

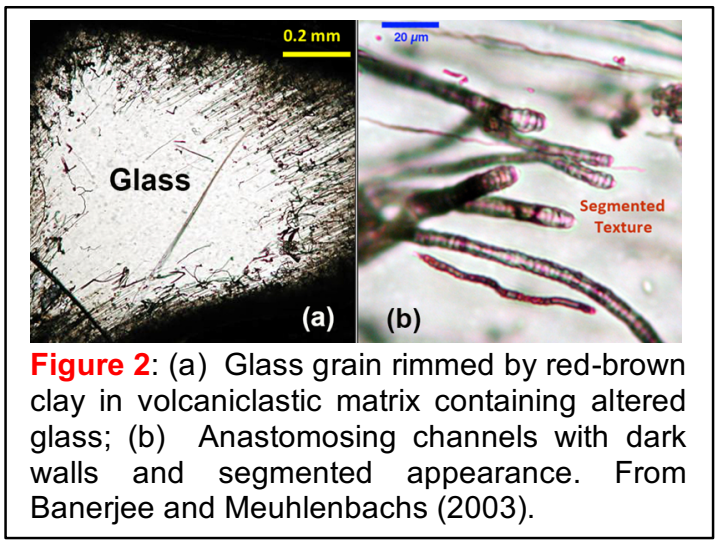

The 2050 Science Framework explores microbial activity through Strategic Objective \#1 (Habitability and Life on Earth) and Flagship Initiative \#5 (Exploring Life and its Origin), which will aid interpretations of data returned from Europa Clipper as it explores another potentially habitable Ocean World. Scientific ocean drilling is also relevant to our understanding of how microorganisms persist despite experiencing at least five major macrofaunal mass extinction events. Scientific ocean drilling has driven our understanding of the Chicxulub impact mass extinction, which has ramifications for understanding how life may have responded in the wake of impact events on other planetary bodies. Through ocean drilling, we attempt to study in great detail the continuum from life to non-life, from organic to inorganic, from rock to water, and biosignatures of life, providing insights into the limits of life on Earth (e.g., Fig. 2; Banerjee and Meuhlenbachs, 2003; Fisk et al., 2019). In this way, more quantitative estimates of life-supporting habitats off-Earth can be constructed and quantified for Mars and Ocean Worlds leading to more targeted missions to explore extinct and extant life possibilities. Scientific ocean drilling provides a natural laboratory for understanding life beyond Earth. Investing in scientific ocean drilling over the next decade is essential for interpreting the habitability and astrobiological potential of other worlds.

Inner Workings of Terrestrial Planets. Plume volcanism is the norm on volcanically-active terrestrial planetary bodies in the Solar System, whereas Earth is unique in that plate tectonics is the main driver of heat loss. However, there are plume-related igneous constructs on Earth that can be investigated and sampled. These include large igneous provinces (flood basalt provinces or LIPs) and hotspot volcanism (Fig. 3).

Evidence for plume volcanism is seen on Mercury (e.g., the Caloris Basin - Head et al., 2011), on Venus (e.g., the Artemis LIP - Hansen, 2007), on the Moon (e.g., Oceanus Procellarum - Neal, 2017), and on Mars (e.g., Tharsis and Elysium Bulges - Keszthelyi and McEwen, 2007). While basalt samples are available from the Moon (returned by US Apollo and USSR Luna missions, and from lunar meteorites) and Mars (the Shergottite meteorites), systematic sampling on planets other than Earth has not been possible. Scientific ocean drilling is critical for proper planetary analogue studies because it retrieves stratigraphic sections and samples materials usually uncontaminated by Earth's unique continental crust. This affords excellent analogue studies (Fig. 3) to better understand planetary 
volcansim. Indeed, magma/lavas sampled through scientific ocean drilling can be directly compared to other terrestrial planetary bodies, where plume volcanism dominates. Through scientific ocean drilling we can explore how plumes physically and chemically evolve, whether their formation contributes to true polar wander (cf. Siegler et al., 2016), and if they can be used to infer mantle heterogeneity. Specifically, drilling provides vital information on plume dynamics in the two dimensions that are most challenging to obtain from extraterrestrial bodies: depth and time. Constraining thicknesses and

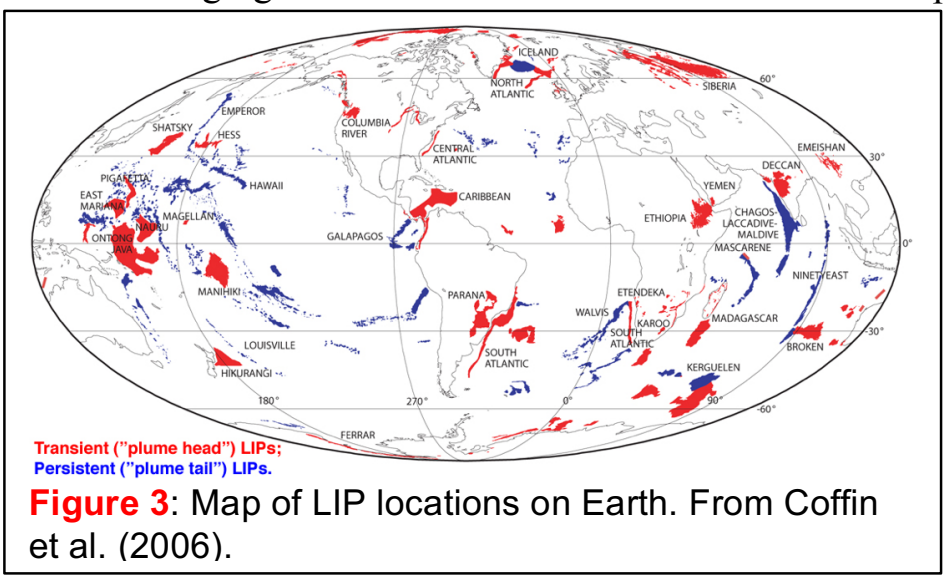

time of emplacement (i.e., rate) for extraterrestrial mantle plume eruptive products can only be done through terrestrial analogues.

The 2050 Science Framework Flagship Initiative \#2 (Probing the Deep Earth) seeks to use plume volcanics to probe the Earth's lower mantle to understand the interior of our planet and the plume process. One of NASA-SMD Planetary Science Division's four major science question is how did the Solar System evolve to its current diverse state? Through analogue studies in collaboration with scientific ocean drilling, NASA can make progress in this area through direct analysis of plume-related magmas obtained from the oceans and uncontaminated by continental crust.

Extraterrestrial Impacts. NASA planetary missions have returned spectacular images and orbital remote sensing data of impact craters and basins, and the Apollo missions returned samples of lunar rocks that were affected by impact processes. On Earth, many impact craters on land have been erased through weathering and erosion. While others are still recognizable as impact-related through shock metamorphism, the crater forms are in various stages of degradation (although there are notable exceptions). In the oceans, however, impact craters younger than $\sim 200 \mathrm{Myr}$ have been buried and preserved. Examples include the late Cretaceous Silver Pit crater in the North Sea (e.g., Stewart and Allen, 2005), the Burkle crater ( 3000 BC) in the Indian Ocean (Abbott et al., 2009; Gusiakov et al., $2009)$, the Plio-Pleistocene ( 2.5 Ma) Eltanin crater off the southern tip of Chile in the Pacific Ocean (Gersonde et al., 1997; Gusiakov et al., 2009), and the Chicxulub impact off the Yucatan peninsula (Alvarez et al., 1980; Hildebrand et al., 1991, 1995; Gulick, Morgan, Mellett et al.,2017). As highlighted in the special issue of Oceanography, many successes and opportunities abound in the study of impact structures by crossing the shoreline and examining the oceans through scientific drilling (Lowery et al., 2019; Gulick et al., 2019a).

The 2050 Science Framework highlights the study of impact craters through the Terrestrial to Extraterrestrial Enabling Element. Scientific ocean drilling will provide greater insight into processes involved in impact crater formation by investigating impact processes through sampling material in three dimensions in and around impact craters, as well as over geological time. This approach will capture the pre-impact conditions, the impact itself, post-impact recovery processes, as well as impactinduced hydrothermal habitats. All these are extremely difficult to explore off-Earth, but scientific ocean drilling will allow us to sample the most valuable impact-generated materials in sedimentary archives dispersed globally on planet Earth or directly within craters themselves. Further understanding of impact processes can drive landing site selection. For instance, peak rings of impact basins represent deeply exhumed lithologies as demonstrated through drilling at the massive Chicxulub crater off of Mexico. Hence, these are potential sites for investigation into crust and mantle rocks otherwise inaccessible on the Moon, Mars or elsewhere (e.g. Fig. 4; Morgan et al., 2016; Kring et al., 2016). 
The study of impact processes is particularly relevant to NASA-SMD-PSD in addressing question $1 \mathrm{a}, 1 \mathrm{~b}$, and $1 \mathrm{~d}$. For example, Chicxulub IODP drilling has explored the recovery of life at the impact site (Lowery et al., 2018; Henehan et al., 2019; Schaefer et al., 2020) and how the impact-generated hydrothermal system developed into a habitat for thermophilic bacteria (Kring et al., 2020; Cockell et al., 2020). Interestingly, a new effort is being planned to drill Chicxulub in the center of the crater, allowing for sampling of the intact melt sheet of the impact and allowing us to ask fundamental questions such as: "do impact melt sheets differentiate?" and "what is the plumbing, longevity, and habitability

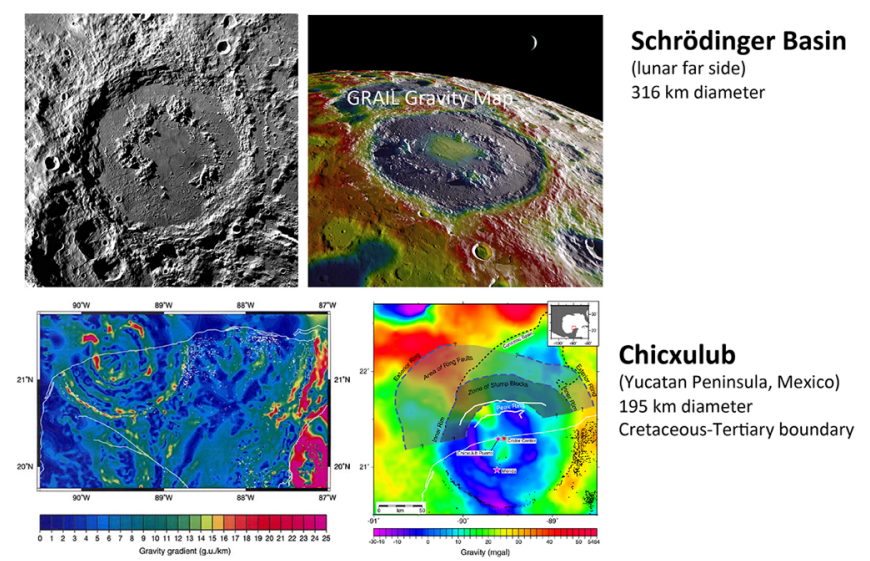

Figure 4: Top: Schrödinger basin from the farside of the Moon (Kring et al., 2016). Bottom: Gravity map of the Chicxulub impact structure Hildebrand et al., 1995; Gulick et al., 2013).

of an impact melt sheet-driven hydrothermal system?" This mission on Earth could be used to facilitate NASA-IODP collaborations. Such research, by offering a holistic picture of life requirements for biogeochemical functioning, will be of particular relevance to search for extra-terrestrial life, in our Solar System and beyond.

Earth's Climate. While this white paper is intended for the Planetary Science Decadal Survey, it also has relevance to NASA-SMD-ESD. The ESD science questions focus on the present and future of the Earth system and climate, and are intimately aligned with the research outlined in the 2050 Science Framework through three Strategic Objectives (\#3 Earth's Climate Factory; \#4 Feedbacks in the Earth System; \#5 Tipping Points in Earth's History) and one Flagship Initiative (\#1 Ground-truthing Future Climate Change). Any collaboration between NASA and NSF/IODP in the area of Earth's climate will also address NASA-SMD Priority 2, Strategy 2.1 Foster a culture that encourages innovation and entrepreneurship across all elements of the SMD portfolio. The integration of modern satellite data (obtained by NASA-SMD-ESD) with records from scientific ocean drilling of the Earth's past climate states can provide a unique framework for improving our understanding of Earth's interconnected dynamic processes and its future climate evolution. For example, has the observed change in climate in the last 50 years been observed in the paleoclimate record derived from the rock cores recovered by scientific ocean drilling? What geologic period(s) are the best analogues for the current situation? What are key tipping points of the Earth climate system that can move atmosphere or ocean dynamics, chemistry, and biology into a new state? On the basis of the results from the last 50 years of ocean drilling, have we sampled those periods in the best places, and if not, where do we go to get the materials needed?

Summary \& Recommendation. Overall, collaboration between NASA and NSF through scientific ocean drilling will strongly benefit both agencies. First, novel information obtained through scientific oceanic drilling with regards to Earth structure, magnetic field evolution, volcanism, habitability, and the requirements for and limits of life will be of particular relevance to understanding planetary evolution and assess the potential for indigenous extraterrestrial life. In addition, paleoclimate data from scientific ocean drilling can increase the value of modern space agency data recording Earth's changing climate. Such a partnership between space agencies and international scientific ocean drilling will also contribute to 1) the development of new technologies and protocols to characterize planetary bodies, detect life signatures and efficiently differentiate extant from extinct forms of life; 2) the testing of these technologies and methodologies in extreme environments on Earth before being deployed for 
robotic space missions; and 3) studying processes and features of other planets in an analogue reference frame on Earth.

\section{References:}

Abbott D. H., et al. (2009) 40 ${ }^{\text {th }}$ Lunar \& Planetary Science Conference, abstract \#2243.

Alvarez L. W., et al. (1980) Science, 208, 1095-1108.

Anonymous (1987). Report of the Second conference on Scientific Ocean Drilling (COSOD II). ESF, Strasbourg.

Banerjee N. R. \& Muehlenbachs K. (2003) Geochem. Geophys. Geosyst., 4(4), 1037, doi:10.1029/2002GC000470.

Christeson, G.L., et al. (2018) Earth \& Planet. Sci. Lett., 495, p. 1-11, doi: 10.1016/j.eps1.2018.05.013.

Cockell, C.S., et al. (2020), Nature Geosciences, in press.

Coffin M.F. \& McKenzie J.A. (2001) Earth, Oceans \& Life: Scientific Investigation of the Earth System using Multiple Drilling Platforms \& New Technologies, 2003-2013. Integrated Ocean Drilling Prog., 120 pp.

Coffin M.F., et al. (2006) Oceanography 19, 150-160.

D’Hondt, S., (2019) Oceanography 32(1), 198-207, doi: 10.5670/oceanog.2019.146.

Dzaugis, M., et al.(2018. Astrobiology 18(9), 1137-1146, doi: 10.1089/ast.2017.1654

Fisk M.R., et al. (2019) Tunnel formation in basalt glass. Astrobiology 19, 132-144.

Früh-Green G.L. \& Orcutt B.N. (2019) Eos, 100, https://doi.org/10.1029/2019EO113213

Gersonde R., et al. (1997) Nature 390, 357-363. https://doi.org/10.1038/37044.

Gulick S.P.S., et al. (2013) Rev. Geophys., 51, 31-52, doi:10.1002/rog.20007

Gulick S.P.S, et al. (2017) Chicxulub: Drilling the K-Pg Impact Crater. IODP. http://dx.doi.org/10.14379/iodp.pr.364.201

Gulick, S.P.S., et al. (2019a) Oceanography 32, 157-159, doi.org/10.5670/oceanog.2019.139.

Gulick, S.P.S., et al. (2019b), Proc Nat. Acad. Sci. 6, www.pnas.org/cgi/doi/10.1073/pnas.1909479116.

Gusiakov V., et al. (2009) In: Beer T. (ed) Geophys. Hazards. Springer, Dordrecht.

Hansen (2007) LIPs on Venus. Chemical Geology 241, 354-374.

Head J.W. et al. (2011) Science 333, 1853-1856.

Henehan M.J., et al. (2019) Proc Nat. Acad. Sci., 116 (45) 22500-22504; DOI: 10.1073/pnas.1905989116.

Hildebrand A. R., et al. (1991) Geology, 19, 867-871.

Hildebrand A. R., et al. (1995) Nature 376: 415-417.

Jones R.M., Goordial J.M., \& Orcutt B.N. (2018) Front. Microbiol. https://doi.org/10.3389/fmicb.2018.01605

Keszthelyi, L., \& McEwen, A. (2007) In The Geology of Mars: Evidence from Earth-Based Analogs, pp. 126150). Cambridge University Press.

Koppers A.A.P. \& Austin J.A., Jr. (2019) Oceanography 32(1), 25.

Koppers A.A.P., et al. (2019) Oceanography 32(1), 14-15, https://doi.org/10.5670/oceanog.2019.108.

Kring, D.A., et al. (2020), Science Advances, 6, eaaz3053, doi.org/10.1126.sciadv.aaz3053.

Lang S.Q. \& Brazelton W.J. (2020) Phil. Trans. R. Soc. A 378: 20180429. http://dx.doi.org/10.1098/rsta.2018.0429

Lowery, C.M., et al. (2018), Nature, 558, p. 288-291, doi:10.1038/s41586-018-0163-6.

Lowery, C., et al. (2019) Oceanography, 32, 120-134, doi.org/10.5670/oceanog.2019.133.

Morgan, J., et al. (2016), Formation of peak rings in large impact craters, Science, 354, 878-882.

Morgan, J.V., et al. (2017), Proc. IODP, 364, College Station TX (IODP), doi:10.14379/iodp.proc.364.103.2017.

NASA Science Mission Directorate (2020) Explore Science 2020-2024: A Vision for Science Excellence.

Neal C.R. (2017) $\mathbf{4 8}^{\text {th }}$ Lunar Planet. Sci. Conf., Houston, TX. Abstract \#1912.

Ocean Drilling Program (1996) Understanding Our Dynamic Earth through Ocean Drilling: Ocean Drilling

Program Long Range Plan Into the 21st Century: Washington (Joint Oceanographic Institutions).

Riller, U., et al. (2018), Nature, 562, p. 511-518, doi: 10.1038/s41586-018-0607-z.

Schaefer, B., et al. (2020) Geology, 48, p. 328-332, doi.org/10.1130/G46799.1.

Schulte P., et al. (2010) Science, 327, 1214-1218, doi:10.1126/science.1177265

Siegler M.A., et al. (2016) Nature 531, 480-484. doi:10.1038/nature17166

Special Issue on Scientific Ocean Drilling (2019) Oceanography 32 (No.1), 248 pp.

Stamenkovic V., et al. (2019) Nature Astronomy 3, 116-120.

Stewart S.A. \& Allen P.J. (2005) GSA Bulletin; 117 (3-4): 354-368. doi: https://doi.org/10.1130/B25591.1 